Est Ag 54 (2019) 141-165

\title{
En las fronteras del cristianismo
}

\author{
TOMÁs MARCos MARTÍNEZ, OSA
}

Resumen: La frontera es tierra de nadie pero también punto de encuentro, un espacio inseguro pero igualmente cauce de integración. La religión ha llegado a su final, exhausta en la carrera del tiempo. El cristianismo, dada su armazón religiosa, ha quedado inevitablemente tocado. Sin embargo, no está hundido. Posee un soplo espiritual invencible, inagotable. Deberá respirar e inspirarse en él con toda determinación, rebuscar y realzar el evangelio original de Jesús. Aun en nuestra época sin religión, la obligación misionera de la Iglesia no cesa, pero habrá de presentar un cristianismo remozado, arreligioso. Solo así podrá llegar a la sociedad moderna, tener algo que ofrecerle, decir algo que pueda ser escuchado. No es una opción, es su única posibilidad.

Claves: Religión, fe, evangelio, misión, ecumenismo espiritual.

Abstract: The border is no man's land but also a meeting point, an insecure space but also a channel of renewal. Religion has come to the end, given out in the race of time. Christianity, due to its religious frame, has necessary been touched. However, it is not sunk. It has an invincible, inexhaustible spiritual breath. He must breathe and be inspired by him with all determination, search and enhance the original gospel of Jesus. Even in our time without religion, the missionary obligation of the Church does not cease, but it will have to present a renewed, no religious Christianity. Only in this way will be able to reach modern society, have something to offer, say something that can be heard. It is not an option, but its only possibility.

Keywords: Religion, faith, gospel, mission, spiritual ecumenism. 
El curtido soldado llega a un lejano fortín militar del oeste, un paisaje ancho y agreste, en medio de la nada. Es un veterano de la guerra civil y acude a la entrevista con el comandante de puesto. Se presenta en el despacho sereno y decidido, con su uniforme azul de botonaduras amarillas, reluciente como si fuera de estreno. El general se le queda mirando atónito, tal que viendo un fantasma.

- Aquí dice que usted es un héroe de guerra -masculla con incredulidad leyendo la hoja de servicios- ¿Cómo ha solicitado este destino, en territorio indio, donde a nadie se le ocurre venir?

Trasluce un deje de amargura, la de quien siente haber llegado al fondo de la derrota. El teniente se sorprende ligeramente de la pregunta. Realmente, sus planes no entran en lo habitual, destilan cierto aire de extravagancia.

- Bueno... -responde con calma, un punto ingenuo, sin pretender convencer-. Solo quiero ver la frontera, antes de que deje de existir. ${ }^{1}$

$* * * * *$

Vivir en la frontera es el sino de nuestro momento. Nuestra época está resultando inequívocamente un enclave de entretierras. Dejando aparte las tremendas mutaciones de la primera mitad del siglo XX (la medicina, la ciencia, la técnica...), en la segunda mitad los cambios han sucedido tan vertiginosamente que sin haber asimilado la transformación anterior ya hemos entrado en la fase siguiente. Vivimos en una frontera permanente, profunda, corrediza. Esto ya se veía así hace 50 años, ${ }^{2}$ pero ahora con la revolución digital la aceleración de los cambios es tal que cada década parece anunciar una edad distinta.

La frontera ha alcanzado también a la religión y la Iglesia. La religión, el conjunto de creencias, normas y ritos que delimitan la adecuada relación con Dios, cede terreno a pasos agigantados ante los avances de la ciencia. Esta cada vez amplía más su saber y pretensiones mientras la religión se muestra supersticiosa y estéril. La creación en siete días y el big bang pueden sentirse a primera vista como teorías fantásticas, pero el relato bíblico se va asumiendo como mítico (en su sentido de filosofía narrativa) en tanto la hipótesis del estallido primigenio se comprueba empíricamente (corrimiento al rojo de las estrellas, radiación de fondo del universo). En cuanto

\footnotetext{
${ }^{1}$ Bailando con lobos, 1990, K. Costner.

${ }^{2}$ L. Suenens, Recuerdos y esperanzas, Valencia 2000, 163.
} 
a la Iglesia, ha cambiado tanto desde el Vaticano II que ni sus impulsores la reconocen: de las misas de fastuosidad latina a las de vulgaridad vernácula, de la obligatoriedad social de la fe a la libertad religiosa, de los templos llenos a la feligresía escasa... La descristianización no es culpa del concilio, protestantes y ortodoxos también la acusan. Son los tiempos cambiantes, es la frontera. De no haberse abierto al mundo, si hubiera permanecido en la condena y confrontación, se encontraría todavía peor: "sin el Vaticano II el futuro de la Iglesia habría sido una auténtica catástrofe". ${ }^{3}$

¿Cómo acomodarse a la nueva situación? El frenesí de los cambios hace que todo parezca provisional. Sin embargo, no podemos enrocarnos dentro de los muros de la tradición y el magisterio, la seguridad de los siglos se desmorona a ojos vista. Hemos de adentrarnos en la tierra de nadie, tener el valor de recorrer los márgenes, ser capaces de no cerrar los ojos y mirar al otro lado, disponernos con audacia a cruzar lo desconocido... Nuestro único bagaje deberá ser la esencia del evangelio, el núcleo de la fe. Retomar la revelación escueta de Jesucristo para ser "sal de la tierra... luz del mundo" (Mt 5,13s). Es lo que podremos ofrecer perennemente, sean cuales sean los tiempos, las culturas, las fronteras.

\section{EL HUNDIMIENTO DE LA RELIGIÓN}

En poco tiempo, la religión ha pasado de vertebrar la cultura occidental, de ser el eje sobre el que pivotaba la organización política, económica y social, a conformar en ella una excrecencia extraña, que se observa con recelo e incluso rechazo. Es asombroso, como entrar en la noche en medio del día, como pasar de súbito del cielo al suelo. ¿Cómo ha sido posible si apenas nos hemos percatado de tamaña involución? ¿Cuándo nos han dado el cambiazo? En algún tramo de nuestra historia reciente, parafraseando al clásico, el orbe despertó un día y descubrió con asombro que era ateo. ${ }^{4}$

\section{Ateísmo masivo}

El ateísmo conforma actualmente un huerto en sazón, tras un breve periodo de cultivo. El agnosticismo y la indiferencia religiosa, aunque téc-

\footnotetext{
${ }^{3}$ F. KöNIG, Iglesia, ¿adónde vas?, Santander 1986, 43.

${ }^{4}$ SAn Jerónimo, Disputa entre un luciferiano y un ortodoxo 19.
} 
nicamente sean distinguibles, no hacen más que ampliar el terreno, conforman la misma irreligiosidad práctica, devenida así de masas. ${ }^{5}$

En la antigüedad la existencia de Dios era una evidencia diáfana a partir de lo creado, como sintetiza san Pablo: "lo que de Dios se puede conocer, está en ellos manifiesto, (...) desde la creación del mundo se deja ver a la inteligencia a través de sus obras" (Rm 1,20). Ciertamente habría explicaciones alternativas, pero eran excepcionales, cosa de "necios" (Sal 14,1), o derivaciones en torno a un "destino" impersonal que se imponía a los dioses, típico de la religiosidad indoirania y grecolatina. La filosofía griega lo reinterpretará más racionalmente como "orden" (el lógos de Heráclito) o "inteligencia" (el noús de Anaxágoras), criticando sobre todo el politeísmo. Estrictamente, el ateísmo filosófico no comienza a apuntarse más que con el atomismo de Demócrito.

Hay que avanzar con botas de siete leguas hasta el siglo XIX para llegar al principio del fin de la mentalidad religiosa. Hasta entonces el mundo occidental había sido creyente de fábrica, por así decir, prácticamente sin la menor objeción. Será Spinoza quien empiece a esparcir las primeras semillas de la increencia -Dios es la naturaleza-, cuyas plantas regarán Feuerbach en el predio de la filosofía -Dios es una proyección humana- y Darwin en el de la ciencia -el azar gobierna el universo-. El siglo XX verá brotar los frutos por doquier y cada vez más, arraigados firmemente en la vida cotidiana. "La negación de Dios o de la religión no constituyen, como en épocas pasadas, un hecho insólito e individual; hoy día, en efecto, se presentan no rara vez como exigencia del progreso científico y de un cierto humanismo nuevo". ${ }^{6}$

El mundo cristiano ha contribuido al proceso arreligioso desde el fideísmo. La Reforma protestante, con su lema de la justificación por la sola fe contrariando las mediaciones institucionales de la Iglesia, conllevó una distinción cada vez más acusada entre la fe individual o confianza en Dios salvador y la religiosidad externa o autocomplacencia mediante obras de piedad sacramentales y canónicas. Será el teólogo reformado Karl Barth quien más se interesará en contraponer la diferencia entre fe y religión. Su

${ }^{5}$ Para lo que sigue, G. Siewerth, Ateísmo: H. Fries (ed), Conceptos fundamentales de la teología, I, Madrid 1966, 175-187; H. FrIEs, Religión: Ibidem, IV, Madrid 1967,70-84; C. GEFFRÉ, Théologie de la religión et du dialogue interreligieux: Catholicisme, XII, Paris 1990, 784802; R. GibELLINI, La teología del siglo XX, Santander 1998, 15-34;115-132.

${ }^{6}$ VATICANO II, Gaudium et spes 7. 
particular teología dialéctica, que resalta al tiempo la necesidad de Dios y la imposibilidad de vislumbrarle, le va a relanzar en ello. Según él, la fe es el abandono en Dios, aposentarse en su amor, más allá de las angustias y oscuridades de la existencia, la espera contra toda esperanza. La religión, en cambio, es un constructo humano, "la temeraria arrogancia del hombre que se estira hacia Dios para así robar a Dios, y con ello apostatar de Dios." La religión es entonces un producto del orgullo del hombre, una crasa idolatría, la impresentable pretensión de controlar lo divino. Por ello, hay que saludar la desaparición de la religión y resaltar la suficiencia de la fe sencilla y sincera.

El teólogo y pastor luterano Dietrich Bonhoeffer se sumará a este rumbo de la aventura, aunque ya no desde la especulación reactiva contra la teología liberal, como en el caso de Barth, sino desde la vivencia dramática del nazismo, la guerra y el mal absoluto. Saludando la llegada de "un mundo mayor de edad", un mundo que empieza a saborear la libertad aunque deba romper con antiquísimas tradiciones, también él defiende "un cristianismo arreligioso". Pero sus escritos últimos, trompicados por la estancia en la cárcel y la amenaza de muerte, apuntes que lamenta no poder pulir, resultan tan intensos como indescifrables. La arreligiosidad que dice percibir alrededor la hace sinónimo de "mundanidad", es decir, de época autosuficiente, que ya no necesita de la religión para comprenderse y saber vivir. Es necesario aceptar este contexto para lograr insertar un nuevo cristianismo, que se concentre simplemente en el seguimiento de Jesucristo, por tanto, en una ética de fraternidad y misericordia, de una parte, y en una mística de afirmación de Dios como "promesa o sentido", sin poderse aquí afinar mucho más. Al igual que Pablo había logrado un cristianismo sin judaísmo es preciso ahora avanzar hacia un cristianismo sin religión. ${ }^{8} \mathrm{Su}$ intuición alucinada y certera, apretada por la asfixia y suplicio de la prisión, nos sigue señalando sin embargo el único camino posible.

La etimología pareciera abundar en esta reflexión. Por un lado, fides indica 'confianza', aceptación, seguridad en algo o alguien más allá de la evidencia. Por otro, religio, pudiendo provenir tanto de religare (atar) como de relegere (revisar) -incluso de reeligere (retomar)-, aludiría de un lado a 'li-

\footnotetext{
${ }^{7}$ K. BARTH, Carta a los Romanos, Madrid 1998, 303.

${ }^{8}$ D. Bonhoeffer, Resistencia y sumisión. Cartas y apuntes desde el cautiverio, 30.IV.1944; 8.VI.1944; 16-18.VII.1944; 21.VIII.1944.
} 
gazón' o vínculo con la divinidad, y de otro a 'ritual' o cumplimiento reiterado y sedante; en realidad, estas dos acepciones no están muy alejadas una de otra, desvelando la religión como una práctica tranquilizadora. Por el contrario, la fe no sirve para apaciguar el espíritu, es una decisión envuelta en la duda, la determinación de avanzar en medio de la tormenta. En todo caso, lo primordial es la fe, y el descrédito de la religión serviría para purificar y renovar la revelación evangélica, que redundaría en una fe limpia, sin adherencias culturales o de tradición, ni políticas o de poder eclesial, ni económicas o de interés lucrativo.

El final de la religión es, de este modo, irreversible. Si bien es un hecho todavía no pleno, se adivina definitivo. Socavada desde fuera por el pensamiento filosófico y científico, corroída desde dentro por el fideísmo cristiano, repulsada culturalmente por el moderno individualismo, su muerte clínica ha quedado certificada socialmente en la revolución de las costumbres de la segunda mitad del siglo XX. Aunque este proceso se haya realizado solo en Occidente, todos cabecean embelesados en su dirección, no porque sea perfecto sino por su envidiado progreso material, así que la suerte está echada. Cual Titanic, la religión se hunde. Es simplemente algo dado, mostrado ostentosamente ante nuestros ojos, que nos sacude cada día la mirada aunque no queramos verlo o ignoremos que lo vemos. Es como un estallido, una fuerza expansiva sin posibilidad de contención.

\section{Funciones de la religión}

Los servicios prestados por la religión son impagables. Más allá de haber sido utilizada como excusa para guerras y desmanes -las guerras no son principalmente religiosas sino más bien territoriales o de poder-, ha ofrecido esquemas de sentido que han hecho posible la supervivencia, convivencia y progreso de la humanidad. Si la imaginación como refugio contra las inclemencias de la realidad ha promovido el pelechamiento del individuo y la especie, si los relatos asumidos colectivamente propician la colaboración de grandes masas, favoreciendo su cohesión, ${ }^{9}$ todo eso ha ofrecido la religión: una creación artística, un ideal por el que vivir y morir. Hegel consideraba la religión una manifestación del espíritu absoluto, una cúspide ideológica humana.

${ }_{9}^{9}$ D. Gilbert, Tropezar con la felicidad, Barcelona 2006, 23ss.232ss. 
Podríamos condensar la utilidad de la religión en torno a tres ejes: 1) explicar el mundo, 2) fundamentar la moral, 3) esperanzar al individuo. Dicha síntesis resuena en orden inverso en el concilio Vaticano II: "Los hombres esperan de las diversas religiones la respuesta a los enigmas recónditos de la condición humana, que hoy como ayer conmueven íntimamente su corazón: ¿Qué es el hombre? (...) ¿Qué es el bien y qué el pecado? (...) ¿Cuál es el último e inefable misterio que envuelve nuestra existencia?"10 Coincidiría además con la trinidad física que aúna las esferas vitales de cada persona: la naturaleza, la sociedad, la individualidad, que como en una auténtica trinidad conforman ámbitos consustanciales e interdependientes.

Dichos tres ejes, abarcando las dimensiones esenciales del hombre, componían los armazones principales sobre los que estructurar la existencia, eran cuestiones de vida o muerte. Pues bien, solo sabía darles cumplida respuesta la religión, con sus mitos, ritos, tradiciones... Solo la religión y nadie más. Únicamente la filosofía intentaba suministrar algunas soluciones parciales, sentidas como incompletas. Hasta que con la Edad Moderna todo empezó a cambiar... Las luces aportadas por la religión fueron recogidas por saberes más especializados, que suministraban claridades más amplias y satisfactorias.

La ciencia experimental asumió la tarea de explicar el mundo. Galileo Galilei, padre de la ciencia moderna al contrastar empíricamente toda hipótesis, primero, y traducirla en lenguaje matemático universal, después, presentará interpretaciones alternativas a las oficiales de la Iglesia sobre el funcionamiento del universo. La más famosa: la rotación de la tierra alrededor del sol y no al revés. Externamente perdió la batalla, se retractó, pero en realidad abrió una puerta que todos utilizarán a partir de ese momento: la de comprender el mundo inmanentemente, lógicamente, experiencialmente. La puerta ofrecida por la Iglesia, la de una comprensión trascendente, revelada, metafísica, será cada vez menos traspuesta. El esfuerzo científico fue descifrando el movimiento de las estrellas y planetas, el origen de las especies biológicas, incluso los mecanismos inconscientes del alma. El universo, la vida, la mente, todo será abordado mucho más convincentemente por la ciencia que por la religión. El progreso y la técnica se deben también a ello. No hay marcha atrás. ${ }^{11}$

\footnotetext{
${ }^{10}$ Nostra aetate 1; ver también J.A. MARINA, Dictamen sobre Dios, Barcelona 2001, 24ss.

${ }^{11}$ J. Monserrat, Hacia el nuevo concilio. El paradigma de la modernidad en la era de la ciencia, Madrid 2010.
} 
Para fundamentar la moral se va a proceder racionalmente y no religiosamente. Rompiendo con la tradición, la época de la Ilustración empezará por desconfiar de lo religioso, fuente de conflictos y supersticiones, como las guerras confesionales y la quema de brujas en Europa. Lo único válido de las religiones es situado en su aportación ética. Pero coligen que esta se apoyará mucho mejor en la común racionalidad humana que en un fideísmo o fanatismo separador. Desde Immanuel Kant la ética autónoma irá imponiéndose como la única moral posible: la ética no necesita de la religión. ${ }^{12}$ La búsqueda de la realización individual y del progreso social se implican mutuamente, el bien común repercute en el bien personal y viceversa, tanto monta un altruismo egoísta como un egoísmo altruista.

Queda por ver cómo esperanzar al individuo. Por una parte único, de un valor absoluto en su irrepetibilidad, que sucede solo una vez en toda la eternidad; por otra parte perecedero, insignificante en la marcha del mundo, un brillo tenue en la inmensidad sin fondo. Cada persona, cada hombre resulta una paradoja de intensidad sofocante. Además, la existencia humana es, mezclada y alternativamente, tanto fuente de dicha como colmo de infortunio. "La vida es bella", se titula una película sobre un judío en un campo de exterminio nazi; "el horror del ser", resume la realidad un filósofo vitalista. ${ }^{13}$ De modo que el sentido de la vida, el consuelo en la noche, es el último soporte que le queda a la religión. Nadie más parece concurrir por la respuesta... de no ser por la psicología actual, que ha decidido entrar al relevo. Retomando viejas nociones del estoicismo y epicureísmo pretende haber encontrado la solución: la existencia ni tiene ni deja de tener sentido, simplemente ha de dárselo cada cual en la vulgaridad y trascendencia de su vida. ${ }^{14}$ Así que incluso en el laberinto insoluble de la existencia individual la religión ha encontrado competencia en pos de una salida.

\section{3. ¿Final del cristianismo?}

La religión se desploma ante nuestros ojos, día a día, golpe a golpe, como se precipita el hielo en los polos por el calentamiento global. Su epifanía más preclara se muestra en la religión cristiana. Pero si esta ha permeado de arriba abajo la cultura occidental, ¿acaso puede disolverse en la

\footnotetext{
${ }^{12}$ V. CAmPs, Breve historia de la ética, Barcelona 2017, 226-251.

${ }^{13}$ La vida es bella, 1997, R. Benigni; F. NIETZSCHE, El nacimiento de la tragedia 3.

${ }^{14}$ A. Ellis, Razón y emoción en psicoterapia, Bilbao 1980, 150ss.
} 
nada? La Iglesia va a cumplir 2000 años de antigüedad, ¿quedarán vestigios solo en monumentos y museos?

De nuevo hay que diferenciar entre fe y religión, espiritualidad e institución. Algunos historiadores contraponen cristianismo y cristiandad para hacer ver que se desmorona solo lo segundo, la organización social cristiana, el seguimiento externo de normas eclesiales. Además de recordar que dicha cristiandad ha sido menos fuerte de lo que se piensa, que ha tenido una influencia más aparente que real, una cristianización impositiva pero no convencida, argumentan que, paradójicamente, esto supone una gran oportunidad para el cristianismo, la ocasión de recuperar su alma primigenia de buena noticia salvífica sin ninguna coacción jurídica. ${ }^{15}$

Por su parte, avezados teólogos ya alertaron a principios de los 70, tras el concilio Vaticano II, del fin de la "Iglesia de masas" hasta ahora conocida, apoyada por las estructuras políticas y la presión social y tradicional, y del advenimiento de una Iglesia minoritaria o "pequeña grey", una "Iglesia de diáspora" resistiendo exigua en un entorno mayoritario hostil o indiferente. ${ }^{16}$

Cincuenta años después, es algo que no necesita grandes estudios ni detalladas estadísticas. Se constata a simple vista. No hay más que observar la media de gente que acude a misa los domingos: cada vez mayor, en edad, y cada vez menor, en cantidad. Se cuantifica en el decreciente número de bodas, bautizos y comuniones que cada parroquia anota en los libros, así como en el creciente número de parroquias que debe atender un mismo párroco a medida que aumentan sus años y disminuyen sus fuerzas. Mismamente al mentar a los familiares y amigos divorciados o descreídos, que antes suponían un escándalo mayúsculo, comidilla de todo el barrio, y que ahora todos tenemos sin excepción, y además en franco auge. Aquí sí que nos topamos con un "fin de ciclo", como truenan los periodistas con cada derrota de la selección de fútbol.

Por no hablar de las películas de cine y series de televisión, el entretenimiento más masivo que existe. Cuando obtienen gran éxito de público, los valores que traslucen quedan indirectamente apoyados, comprendidos o tolerados. Pues bien, por poner un ejemplo, El paciente inglés, 1996, hermosa película ambientada en la II Guerra Mundial, que recibió 9 Oscar e incontables millones de espectadores, presenta apologéticamente historias

${ }^{15}$ Así J. Delumeau, Le christianisme va-t-il-mourir?, Paris 1977, retomado y traducido posteriormente en un nuevo libro, El cristianismo del futuro, Bilbao 2006.

${ }^{16}$ Por ejemplo, K. RAHner, Cambio estructural en la Iglesia, Madrid 1974, 31-43. 
dolorosas de adulterio, suicidio, homosexualidad y eutanasia. En dos horas se ha cargado la moral de la Iglesia con la aquiescencia de medio mundo. El otro medio no ha visto la película por vivir arrojado en los márgenes tercermundistas.

Pero echemos mano de las estadísticas, que no se diga que no somos científicos. Según las últimas encuestas sobre religiosidad, se definen católicos en España el 67,5\%. Uno pensaría: 'bueno, no está mal'; pero a la siguiente pregunta, que inquiere a los que se han afirmado católicos sobre su asistencia a actos religiosos, responde "casi nunca" el 62,1\%. Entonces nos quedamos bizcos. Puestos a escudriñar la práctica religiosa por la asistencia a misa -quitando los compromisos de cumplimiento (bodas, bautizos, funerales) en los que el sacerdote siente que habla a las paredes-, responden variopintamente, "varias veces a la semana": $2,7 \%$, "casi todos los domingos": 13,4\%, "alguna vez al mes": 8,8\%, "varias veces al año": 11,5\%. Incluso los que somos de letras entendemos que los católicos medianamente practicantes apenas compondrían un escuálido $25 \%$. Por si esto fuera poco, del total de nacimientos parece que son bautizados poco más del $50 \%$. Y para rematar, sólo el $20 \%$ de los que se casan lo hace por la Iglesia frente al $80 \%$ de matrimonios civiles, justo al revés que hace 30 años. ${ }^{17}$ Cifras raquíticas, alarmantes, para la ideología que señoreó Occidente. Los dinosaurios también dominaron la tierra.

Ya se sabe que las estadísticas, como el bikini, enseñan todo menos lo importante, que si en un restaurante han pasado 4 clientes y se han consumido 2 pollos concluyen que cada persona ha comido medio pollo, obviando que un gordo puede haber tragado uno entero o un niño haber tirado su parte al tiesto más cercano. Con todo, nadie puede discutir su fiabilidad. Que acudan si no a ámbitos tan sensibles como la política o el comercio, donde partidos parlamentarios y empresas publicitarias se juegan la vida, donde ambulan de por medio el poder y el dinero, los dueños del mundo. Que les insinúen, como quien no quiere la cosa, si acaso se preocupan de desmenuzar los sondeos de voto antes de las elecciones o de vigilar los decimales de la cuota televisiva de pantalla. Ante los demoledores resultados de las encuestas sobre religiosidad cristiana, cuya progresión a la baja se evidencia irrefrenable, ¿qué hacer? ¿El último, que apague la luz?

${ }^{17}$ CIS, Barómetro de febrero 2019; INE, España en cifras 2018, 10-12; CEE, Memoria anual de actividades de la Iglesia católica año 2016, 38; Informe Ferrer i Guàrdia 2018, 143ss. 
La pregunta grave no sería si va a desaparecer la Iglesia, con serlo de todos modos, la cuestión apocalíptica es si desaparecerá el cristianismo. En realidad, esta es la única pregunta. La Iglesia depende del cristianismo, solo existe desde y para él, no podría mantenerse sin él más que negándose a sí misma -siendo solo estructura de poder-, con lo que de todos modos se destruiría. Claro que la fe cristiana tampoco puede subsistir sin la Iglesia, sin una comunidad que la cuide, la celebre, la transmita, la testimonie. Pero en todo caso no salimos de la cuestión clave: ¿tiene futuro el cristianismo?

La respuesta es afirmativa, pero no va a ser muy consoladora, para muchos quizá tampoco aceptable. Tal vez es solo medio afirmativa. Es decir, va a ser en todo caso dolorosa, admitiendo que nos encontramos en una frontera de confines inciertos, parecida a una senda improvisada sobre el abismo en la que ya no es posible retroceder: volver a las antiguas creencias y tradiciones; pero avanzar semeja una huida hacia adelante: un cristianismo solo espiritual, sin dogmas, ritos ni instituciones.

\section{Cristianismo espiritual}

El cristianismo dogmático se deslíe abrasivamente en nuestra época arreligiosa. Los dogmas se parecen a las reliquias, permanecen venerables, pero siempre encerradas en su urna. Los más elementales, los del credo apostólico, apenas logran ser recitados por los fieles de la misa dominical. Para el cristiano medio, trinidad, encarnación, resurrección, resultan conceptos reconocibles, pero ya no nucleares o identitarios, parecieran adornos externos, como la navidad o la semana santa, que los puede asumir cualquiera de un modo distante o neutral. ${ }^{18}$ Y no hablemos del pecado original o de la virginidad de María, creencias arrumbadas en lo folclórico o extravagante.

Sin pretender convertir la anécdota en ciencia, en un grupo parroquial de oración, con la lectio divina de la anunciación, unas quince personas, la mayoría mujeres, de edad más que madura, cristianas de toda la vida, manifestaron abiertamente sus dudas sobre el ángel y la concepción virginal. Boquiabierto, balbuceante, hablé incluso de géneros literarios, de seguir el mensaje más que la literalidad... Sí, la sociedad occidental está muy secularizada, pero ahora ¿se me estaba revelando la zarza ardiente de la descristianización de los cristianos?

${ }^{18}$ L. GonZÁlez-CARvajAl, El Credo explicado a los cristianos un poco escépticos (y a los escépticos un poco cristianos), Santander 2019,9-15. 
Desde luego, no se trata de escamotear la dogmática tradicional como si fuera material desechable: es la elaboración teológica, depurada por la razón y testada por generaciones, de la fe cristiana. Pero siguiendo el concepto de la evolución de los dogmas, es decir, actualizar la forma de expresarlos sin variar su contenido central ¿no sería el momento de resaltar su intención simbólica, su profundidad metafórica? San Pablo explicó la encarnación divina como kénosis, esto es, 'vaciamiento' de su omnipotencia para identificarse con la poquedad humana (Flp 2,6s). San Juan compendió la cristología como Lógos hecho carne, por tanto, la razón, la palabra de Dios manifestada al hombre, hecha 'revelación' (Jn 1,1ss). San Agustín, por su parte, analogó la trinidad divina con el alma humana, en cuanto hecha a su imagen y semejanza, para sugerir dialécticamente la radical comunicabilidad y la enigmática inaccesibilidad de ambas. ${ }^{19}$

El cristianismo litúrgico se destartala sin remedio como un armazón carcomido por los tiempos. Las fiestas se han desustanciado completamente en su contenido aunque continúen marcando los ritmos anuales. La navidad es tiempo de comidas familiares y regalos, la semana santa consiste en procesiones costumbristas de tallas y cornetas, cuaresma y pascua son sonidos en busca de significado. De las celebraciones de los santos apenas queda huella en almanaques y refranes; y si los domingos señalan una pausa universal, para nada es religiosa, según su origen, sino solo laboral, parte del fin de semana. Sin rementar las devociones populares del rosario, adoración al Santísimo y procesiones, idas con los abuelos.

Los sacramentos ya no miden como antes la marcha religiosa de cada persona. El bautismo adolece de su conexión con el pecado original, que arrastra a aquel en su caída; la confirmación incluso se da por desaparecida en muchas diócesis, no la exigen para el matrimonio; la penitencia es un reducto de mentes escrupulosas, cuando no un counseling gratuito ante conmociones pasajeras; y la unción de enfermos se desangra en lucha con la extremaunción, que sigue funcionando como preaviso de defunción. La eucaristía es un quiero y no puedo creyente, una participación en general pasiva de escuchar, sentarse y levantarse. Paradójicamente, solo matrimonio y Orden están señalando, justamente en su tremenda disminución, lo que debieran indicar los sacramentos: una solicitud desinteresada y consciente.

El cristianismo sociológico, hermano gemelo del anterior, conlleva su misma apariencia, pensamiento y emoción. Las normas cristianas, la disci-

${ }^{19}$ La Trinidad 9,4.18; 10,18s. 
plina eclesial, van pasando sigilosamente a mejor vida. Eucaristía semanal y penitencia anual cumplen por lo común poco consigo mismas. Y mucho menos respecto a las disposiciones sobre anticonceptivos, trascordadas generalizadamente sin conciencia de culpa. El ayuno y la abstinencia se ignoran en su mismo significado, el primero suena a no picar entre comidas, cual dieta para adelgazar, y el segundo recuerda al 'derecho a decidir': falta determinar (de) qué. Los cristianos no practicantes, tan mayoritarios en las encuestas religiosas, definen el cristianismo sociológico de toda la vida: una educación cristiana genérica con cierto peso en las costumbres cotidianas, pero ahora se han agudizado en su literalidad: no practican en absoluto, en realidad no son cristianos.

Solo nos quedaría el cristianismo ético, un cristianismo espiritual o existencial, basado no tanto en el cumplimiento de reglas externas cuanto en el comportamiento según convicciones vitales. Consistiría en interiorizar los valores del evangelio, "adorar a Dios en espíritu y verdad" (Jn 4,24), lo que la renovación de la ética teológica distinguía como opción fundamental, cambiar una moral de actos por una moral de actitudes. ${ }^{20}$ Pareciera la última bala, casi una solución desesperada, pero en realidad es la única baza de siempre, el núcleo de la fe cristiana.

El cristianismo religioso se desvanece lánguidamente, con las venas abiertas. Es necesario cortar la hemorragia, convalecer en la oscuridad, aventurarse en la frontera: un cristianismo existencial sin más, sin cristianismo doctrinal ni cristianismo socio-litúrgico. ¿Es esto posible? ¿No se derrumba lo uno sin lo otro? ¿Es factible vivir unos valores sin fundamentación teórica, primero, y sin alimentación comunitaria, después? Tal vez no lo es enteramente, pero quizá sí lo es en parte. He aquí la cuestión. Se trataría entonces de ajustar lo fundamental en ambos, de destilar la quintaesencia del cristianismo y de la Iglesia.

\section{ETERNIDAD DEL EVANGELIO}

El cristianismo nació con dos almas, padece cierta bipolaridad, lo que en su caso no supone una enfermedad grave, aunque sí le genera algunos achaques. Esta duplicidad está patente en la figura del fundador: nacido

${ }^{20}$ M. VIDAL, Moral de actitudes, I. Moral fundamental, Madrid 1981, 120ss. 
Jesús, en hebreo 'Yahvé salva', lo que fue el centro de su actividad (Mt 1,21), será llamado después Cristo, en griego 'ungido', la referencia venida de Dios (Mc 8,29). Como no cabía duda de que eran la misma persona, es más, de que ambos rasgos no podían entenderse separadamente, será redenominado Jesucristo, algo así como hombre divino (1Cor 1,1s). Mucho tiempo después, el racionalismo crítico de la teología liberal decimonónica empezará a percibir cierta cesura entre el primer y segundo paso, dudando entonces del tercero. Una cosa es la vida de Jesús y otra la interpretación de su pascua, que inevitablemente reinterpretó su vida. Del Jesús predicador del reino al Cristo predicado por su resurrección hay un trecho, debe distinguirse el "Jesús histórico" del "Cristo de la fe". Pues bien, sin poderlos separar, ambos aspectos no se decantan de la misma manera, poseen su identidad propia, su intransferible mismidad. ${ }^{21}$

\section{El evangelio de Jesús}

El motivo de la aparición pública de Jesús, como es sabido, fue la proclamación del reinado de Dios: "he sido enviado a anunciar la buena nueva del reino de Dios" (Lc 4,43). Es decir, la predicación de la presencia de Dios, en su aquí y ahora, será el núcleo de la actividad de Jesús. Efectivamente, todo lo que hizo y dijo se entiende solo desde el mensaje del reino: el significado de las parábolas, de otro modo enigmáticas (Mc 4,11s) pero diáfanas en cuanto explicaciones de este anuncio (Mt 4,30); la consistencia de los milagros, mayormente curaciones porque muestran la fuerza sanadora del poder divino (Lc 11,20); la expectativa mesiánica que generó, un revuelo religioso, político y social (Jn 11,48); la motivación de su condena, escrita en un letrero sobre su cruz (Mc 15,26)... todo remite al testimonio de un reinado especial, una manifestación o majestad de Dios que se traslucía y trasmitía a través de su persona.

¿Qué es el reino de Dios? Más que buscar una definición filosófico-religiosa deberemos mirar la figura misma de Jesús, el conjunto de su acción, dado que aquel se expresa principalmente en este. ${ }^{22}$

En primer lugar, Jesús anuncia la cercanía del reino como buena nueva, eu-aggélion (Mc 1,15), palabra tan asociada a su misión que servirá para

${ }^{21}$ S. GUIJARro, El significado del término euaggelion en los comienzos del cristianismo: Estudio Agustiniano 52 (2017) 123-143.

${ }^{22}$ Sobre esto, J. Jeremias, Teología del Nuevo Testamento, I, Salamanca 1973, 119ss; Abba y el mensaje central del Nuevo Testamento, Salamanca 1981, 19-89. 
denominar el relato entero de su vida (Mc 1,1). Es lo que le distingue de Juan Bautista y los profetas, para quienes la venida de Dios conllevaba juicio, por tanto, al tiempo redención y castigo. Jesús difunde, en cambio, solo alegría y acogida, una especie de oferta desinteresada general de parte de Dios. Por eso se abre también, con sorprendente igualdad, a pecadores, pobres, enfermos, gentiles (infieles), mujeres y niños, a todo el abanico de la marginalidad social judaica.

El Dios del reino que menciona lo entiende sobre todo como Padre al modo en que los niños lo hacen: 'abba, 'pa-pa', asumido así como apelativo afectuoso. Repetiría tanto esa palabra que se ha conservado como un islote aramaico en el mar griego del nuevo testamento ( $\mathrm{Gal} 4,6)$. Llamar a Dios papá hoy nos sonará un poco cursi, pero entonces discordaba sobre todo como escandaloso e irreverente. En todo caso, implica un Dios cercano y cariñoso, de una misericordia y perdón impensables, que inquietan nuestros cálculos, como se evidencia en las parábolas del hijo pródigo o de los viñadores de última hora (Lc 15,11ss; Mt 20,1ss).

Así pues, dos extranjerismos vienen a describir el significado del reino de Dios: evangelio y abbá, buena noticia y bondad protectora. En resumen, el reino de Dios es evangelio porque el Dios del reino es Padre. Señala básicamente la gracia de Dios, el amor de Dios hacia sus criaturas. Esta concepción, a fin de cuentas, es una actitud, algo así como un optimismo preventivo, basado en la creencia en un Dios favorable, que invita a encarar la vida con esperanza. En absoluto es un buenismo cándido que ignora las dificultades de la vida, sino todo lo contrario, una confianza plena en la providencia divina sabiendo que "cada día tiene su propio mal" (Mt 6,34).

En segundo lugar, Jesús buscaba con la predicación sobre el reino la regeneración de Israel, sacudir su conciencia. Su exclamación de la llegada del reino prosigue: "convertíos, creed la buena noticia" (Mc 1,15). Cuando le inquirieron en qué se concretaban sus llamadas a la renovación replicó con dos deberes. "El primero es: amarás al Señor, tu Dios, con todo tu corazón, con toda tu alma, con todas tus fuerzas. El segundo es: amarás a tu prójimo como a ti mismo" (Mc 12,30s). Son dos citas tomadas de la ley veterotestamentaria, de la tradición religiosa de Israel (Dt 6,5; Lv 19,18), pero Jesús las reinterpreta a su modo: por un lado, las hace indisociables; por otro, amplía al máximo la idea de prójimo.

Que los dos mandatos son en realidad uno lo entendieron bien sus discípulos de primera hora: "amar al prójimo es cumplir la ley entera", escribe Pablo (Rm 13,8), "quien no ama a su hermano, a quien ve, no puede amar 
a Dios, a quien no ve", ratifica la comunidad joánica (1Jn 4,20). Esto significa que el culto a Dios incluye necesariamente la defensa del hombre, y al revés, que quien promueve el valor principal del ser humano está también adorando a Dios.

Amar al prójimo es por tanto el primero o el último o el único fundamento del cristianismo. El prójimo es evidentemente el próximo, quien está a tu lado ordinariamente, tu familia y amigos y compatriotas (a lo que se refiere Lv 19,18), pues el amor se expresa bien en los lazos de sangre, la lealtad amistosa, la abnegación patriótica. Pero Jesús ensancha el concepto de prójimo a cualquiera que uno encuentra en su camino, sobre todo si está postergado. A la pregunta “¿quién es mi prójimo?” responde con la parábola del buen samaritano: prójimo es quien te necesita (Lc 10,29ss). El amor se entiende aquí como misericordia, brota de una conciencia de igualdad humana en la que el otro ha quedado en posición de debilidad. Mas la projimidad que pide Jesús es estirada al límite al alcanzar también a quien te desea mal, al enemigo (Mt 5,44). El amor queda así convertido en altruismo, en un valor en sí, independiente de la respuesta ajena. En conclusión, prójimo es cualquier persona, en la condición que sea, todos los hombres somos prójimos, semejantes, unos de otros.

Muchas veces se ha hablado de la caridad como la médula del cristianismo, desde el antiquísimo himno de san Pablo (1Cor 13,1ss) hasta las especulaciones de la teología actual. ${ }^{23} \mathrm{Sin}$ pretender arrogancias y reconociendo imperfecciones, su práctica queda ejemplificada en las instituciones benéficas que escalonan la historia de la Iglesia, abarcando todos los ámbitos: hospitales, orfanatos, albergues, escuelas pías, montes de piedad... Asimismo, se hace patente en las organizaciones modernas de voluntariado y donaciones: cáritas, domund, medicus mundi, fundaciones pro misión... Realizándolo mejor, regular o peor, la caridad ha sido integrada como parte consustancial de la fe cristiana. ${ }^{24}$

Concluyendo esta sección, el evangelio de Jesús conforma dos caras en la misma moneda. Una mística, expresada como reino de Dios, llena de esperanza en el futuro y de agradecimiento por el presente, avalados por un Dios de salvación que siempre es gracia. Y otra ética, perfilada como amor al prójimo, convertido en el eje del comportamiento humano, la fraternidad universal practicada como misericordia y altruismo. Amor de Dios y amor

\footnotetext{
${ }^{23}$ B. FORTE, La esencia del cristianismo, Salamanca 2002, 159-183.

${ }^{24}$ J.M. LABOA, Por sus frutos los conoceréis. Historia de la caridad en la Iglesia, Madrid 2011.
} 
al prójimo. Para la fe cristiana estos dos elementos resultan inclusivos e interdependientes. Mística sin ética es una abstrusión ensimismada, una metafísica aérea incapaz de aterrizar. Ética sin mística es un ideal derrotado, una decepción segura dado el egoísmo y limitación humanos.

Por todo ello el cristianismo es eterno, no puede morir. Subsistirá mientras exista la humanidad, pues ha tocado las dos fibras que sostienen la vida del hombre: la esperanza y la fraternidad. Como ha sido dicho hace tanto, anima naturaliter christiana. ${ }^{25}$

\section{El evangelio sobre Jesucristo}

"El evangelio de Cristo" (Rm 15,19), en genitivo objetivo, la predicación sobre su persona y significado, se concentra en la experiencia pascual, la resurrección. El kerigma más antiguo, el primer anuncio apostólico, reza así: "Os recuerdo, hermanos, el evangelio que os proclamé. (...) Os transmití, en primer lugar, lo que a mi vez recibí: que Cristo murió por nuestros pecados, según las Escrituras; que fue sepultado y que resucitó al tercer día, según las Escrituras" (1Cor 15,1.3).

Se destilan tres gotas de esencia en este kerigma. Primero e implícitamente: Jesús es el Cristo, el ungido, esto es, el mesías de la expectativa judía, el enviado definitivo de Dios en traducción para los gentiles. Segundo: su muerte es redentora, liberadora, rescate de nuestras maldades y miserias. Y en tercer lugar: ha resucitado de entre los muertos, Dios ha reivindicado y exaltado su figura. Ahora bien, aunque tal vez es un círculo en el que no hay punto claro de partida, todo encuentra impulso y criterio desde el tercer elemento: la resurrección de Jesús dilucida su muerte como redención y descubre su misterio como el Hijo de Dios.

La resurrección, por tanto, lo decide todo. No es que valga por sí sola sino que es la luz que ilumina lo demás, que hace captarlo todo. A saber: redescubre a la persona terrena como referencia para guiar a la humanidad, "fijos los ojos en Jesús, el que inicia y consuma la fe" (Hb 12,2); le aplica la noción de Logos, la Palabra eterna de Dios, porque es su revelación plena y definitiva (Jn 1,1ss); le señala como el redentor, pues murió por nosotros, defendiendo la causa humana, compensando nuestros pecados, haciéndonos así propicio a Dios, de modo análogo pero eminente respecto de los sacrificios del Antiguo Testamento (Rm 3,24s). Estas convicciones marcarán

${ }^{25}$ Tertuliano, Apología 17,6. 
el nacimiento de la Iglesia, la reagrupación de los discípulos huidos tras el desastre del prendimiento y ejecución $(\mathrm{Mc} 14,50)$ y su posterior e intensa responsabilidad misionera: "Id por todo el mundo y proclamad la buena nueva a toda la creación" (Mc 16,15).

Además, la resurrección no es algo neutro, que haya sucedido a Jesús y que podamos observar desde fuera simplemente alegrándonos por él. Tiene que ver con nosotros, si creemos en él y seguimos su ejemplo heredaremos su destino: "si morimos con Cristo, viviremos con él" ( $\mathrm{Rm} \mathrm{6,8).} \mathrm{La}$ resurrección de Jesús es promesa para los creyentes, participación en su plenitud: "si confiesas con tus labios que Jesús es el Señor y crees en tu corazón que Dios le resucitó de entre los muertos, te salvarás" (Rm 10,9). De modo que la resurrección de Jesús es "primicia de los que duermen" (1Cor 15,20), anuncio de salvación universal.

La resurrección pasará así a ser "el evangelio de Dios" (Rm 1,1), la nueva esencia del cristianismo, por la que se derrumba o sostiene la fe, casi diríamos. Como asevera Pablo: "si Cristo no ha resucitado vana es vuestra fe" (1Cor 15,14.17). Así será a partir de entonces a lo largo de toda la historia de la Iglesia. La resurrección devendrá el símbolo, el resumen, la concreción de la salvación. Según dice san Agustín en polémica con el pelagianismo: "en la cuestión de dos hombres, Adán y Cristo, consiste propiamente la fe cristiana". ${ }^{26}$ Es decir, en ellos se condensa la doctrina creyente y la explicación de la existencia: precipitada la humanidad irreparablemente en el pecado mediante uno, pero sin embargo rescatada graciosamente para la vida eterna en el otro.

Pues bien, sería llegado el momento de volver al evangelio de Jesús nazareno, el de la esperanza y fraternidad, de algún modo relegado ante la pujanza del evangelio de Cristo resucitado. Al fin y al cabo, la resurrección como evangelio escatológico es una actualización del evangelio histórico: la salvación de Dios que Jesús proclamaba ya presente en su vida terrena ha sido hecha realidad de modo definitivo al ser recobrado del abrazo de la muerte y quedar extendida como horizonte para todos los fieles. El evangelio primero ha sido asumido con tal fuerza por el evangelio segundo que ha quedado subsumido en este. Pero el segundo paso siempre viene después del primero, y quizá no siempre tendrá la misma aclamación. ${ }^{27}$

${ }^{26}$ La gracia de Cristo y el pecado original 2,28.

${ }^{27}$ J.A. EstradA, De la salvación a un proyecto de sentido. Por una cristología actual, Bilbao 2013. 
En nuestro tiempo descreído, en el que la religión ha decaído en su función de explicar el mundo o dirigir el comportamiento correcto, en los que solo puede colaborar en la búsqueda del sentido de la vida, la única posibilidad del cristianismo es una nueva actualización, en este caso arreligiosa, reinterpretar su fe retornando al evangelio primigenio. No se trata de eliminar la dogmática ni la liturgia ni la canonística, sino de encauzarlas para la tarea de construir puentes, de encontrar un terreno común con la mentalidad y cultura modernas.

\section{LA MITAD DE LA FE}

Si la religión avanza por un callejón sin salida, el cristianismo nuclear por el contrario tiene vía libre, sus valores de esperanza y fraternidad son inmarcesibles, tejen el alma misma de la humanidad. Dichos valores habrán de encontrar una colaboración natural, congeniar con una espiritualidad laica.

\section{Ecumenismo espiritual}

Proveniente del griego oikeín, 'habitar', el participio oikouméne, 'lo habitado', indicará el mundo, y su adjetivación posterior, oikoumenikós, servirá para calificar el concilio de Nicea como 'mundial', dado que había representantes de la Iglesia entera, cuyas definiciones valían para todo el imperio. El término revivirá a finales del siglo XIX con otro matiz, al aplicarse al esfuerzo de integración de 'todas' las confesiones cristianas. ${ }^{28}$ La derivación última en ecumenismo servirá entonces para denominar algo así como 'unionismo', voluntad de cohesión. Ecce unde.

Ha costado sangre y siglos, pero hoy ya nadie discute la necesidad del ecumenismo cristiano, la obligada colaboración entre sus distintas confesiones basada en lo mucho que tienen en común. Nacieron en acerada división, incendiando sociedades y guerras, y se multiplicaron endurecidas por el odio. Sin embargo, nunca aflojaron en el mantenimiento de idéntica fe central: la Biblia como palabra revelada, los sacramentos mayores del bautismo y la eucaristía, los antiguos Credos basados en la trinidad, reden-

\footnotetext{
${ }^{28}$ J. Bosch, Para comprender el ecumenismo, Estella 1991, 9-12.
} 
ción, Iglesia y vida eterna. ${ }^{29}$ Era obligado e inevitable el acercamiento y trabajo de reconciliación.

Con mucho menor dramatismo, pero con enconadas discusiones académicas, algo parecido podría decirse del ecumenismo religioso, la bondad del diálogo entre religiones, denominado también teología de las religiones o del pluralismo religioso. Está basado en la convergencia de las diversas concreciones de la revelación divina. Todavía en polémica, se ha ido pasando del exclusivismo religioso, cada una se ufanaba de la tenencia de verdad absoluta excluyendo a las demás, al inclusivismo religioso, que admite en las otras parte de verdad conservando una misma la plenitud, apuntando en último análisis al pluralismo religioso: todas poseen de distinta manera la única revelación divina. ${ }^{30}$ En todo caso, por tanto, al tener idéntico origen y vocación, las religiones se deben mutuo conocimiento, respeto y colaboración.

El último paso en este camino debiera ser el ecumenismo espiritual, la búsqueda común del alimento que precisa el espíritu humano. Un ecumenismo eficaz, como todo pacto, es un encuentro en el que las dos partes han de ceder. No se renuncia a las propias ideas sino a que todas deban ser aceptadas por el interlocutor, se parte de las comunes para así marchar, tal vez lentamente, pero avanzar. Consistiría aquí en la asociación de un cristianismo no religioso, centrado en el evangelio prístino de mística y ética, con la espiritualidad profana, una mentalidad tal vez agnóstica o no creyente pero abierta al misterio del mundo, el bien común y la felicidad personal. ${ }^{31}$

No queda otra oportunidad de mediación, dado el desencuentro entre instituciones religiosas y mentalidad no religiosa. Esto no tiene que consistir para los cristianos en quedarse solo con la mitad de la fe desistiendo de la otra mitad. Se trata simplemente de tender al fundamento conjunto, a la parte espiritual que todos podrían compartir. Al fin y al cabo, la Iglesia no puede cejar en su tarea testimonial, que conforma su mismo ser. Tendrá entonces que asumir el mundo arreligioso contemporáneo, mal que le pese, aggiornando su esfuerzo misionero en vistas a la inteligibilidad de su anuncio y la conexión con la sociedad moderna.

${ }^{29}$ VATICANO II, Unitatis redintegratio 20-22; Lumen gentium 15.

${ }^{30}$ Tras el exclusivismo tradicional, el Vaticano II abrazó el inclusivismo (LG 16; NA 2). $\mathrm{El}$ anglicano J. Hick ha propuesto el pluralismo (God and the Universe of Faiths, New York 1973), pero su variante católica (J. DuPUIS, Vers une théologie chrétienne du pluralisme religieux, Paris 1997) ha sido puesta en entredicho, pues suena a relativismo religioso.

${ }^{31}$ A. Comte-Sponville, El alma del ateísmo. Introducción a una espiritualidad sin Dios, Barcelona 2006. 
El judaísmo entendía que su luz esplendente atraería los pueblos hacia sí (Is 2,2ss). El islamismo impulsó su expansión como instrumento teocrático. Sólo el cristianismo se sentirá obligado a abrirse, sin complacencia ni conquista. ¿A qué se debe tal propulsión misionera? Justamente a la ósmosis evangélica del amor de Dios y el amor al prójimo. La Iglesia se entenderá obligadamente misionera porque conocer la buena noticia y tener el mandamiento de la fraternidad no le deja otra opción: "predicar el evangelio es un deber que me incumbe" $(1$ Cor 9,16). Desde el primer momento y hasta hoy los creyentes saben que el Señor les urge: "id por todo el mundo y proclamad la buena nueva a toda la creación" (Mc 16,15). La médula de su fe conlleva un intrínseco testimonio, tanto espontáneo e individual como estructurado y colectivo, "la Iglesia es esencialmente misionera."32

El cristianismo del futuro deberá acometer "una Iglesia abierta también con respecto a la ortodoxia"'33 En otras palabras, hay que aceptar como supuesto el pluralismo social, que cada uno pueda seguir su conciencia y credo sin vetos ni imposiciones. Tendrá que hacerlo en lo que se refiere a los disidentes internos, cuya autonomía y responsabilidad se ha de respetar y promover, y extenderlo también a los simpatizantes externos, a los que sin ser creyentes se sienten parcialmente identificados con la fe y valores cristianos. Como dice el evangelio: "el que no está contra nosotros está con nosotros" (Mc 9,40). Sobre disidencia interior, oí una vez a un joven comprometido con la acción eclesial criticar algunas posturas de la Iglesia jerárquica: "me pasa con la Iglesia como con mi madre", comentaba, "yo la quiero y respeto, pero soy mayor de edad, no puedo seguir pensando ni haciendo exactamente lo mismo que ella dice y hace".

El cristianismo es misionero por entraña, por constitución. Pero la misión precisa una Iglesia, una comunidad organizada para ello: "Dios los puso en la Iglesia primeramente como misioneros" (1Cor 12,28). Así las cosas, los signos de los tiempos la fuerzan a una misión arreligiosa.

\section{El sentido es la esperanza}

El hombre es interrogación sobre las cosas. Es inevitable: un ser pensante confrontado con el mundo hervirá en un “¿por qué?”. Requerimiento sobre el enigma de la existencia, admiración ante la realidad, estructura-

\footnotetext{
${ }^{32}$ Vaticano II, Ad gentes 2.

${ }^{33}$ K. RAHner, Cambio estructural de la Iglesia, Madrid 1974, 115.
} 
ción de la diversidad caótica... tal ha sido el comienzo de la filosofía, como dejó constancia para siempre Platón. ${ }^{34}$ Pero mucho antes, la misma cuestión había supuesto el nacimiento de la religión: las antiquísimas teogonías y mitologías, como el Enuma Elish babilónico, fechado en el siglo XIII aC, se esfuerzan en descifrar el origen y desarrollo del universo. Y muchísimo después, la psicología empírica percibe la curiosidad como una necesidad biológica: la perenne insatisfacción humana es el motor de su progreso, pues de otro modo quedaría paralizado en la autocomplacencia. ${ }^{35}$ Por tanto, teología, filosofía y ciencia moderna coinciden en situar en el centro de lo humano la pregunta por la realidad y su fundamento, la pregunta por el ser.

¿Tiene sentido la vida? Silencio administrativo. No hay respuesta. Sentido, dirección o significado parecen presuponer pensamiento, pero el universo no es pensante. Lo existente simplemente existe, "el ser es", como sintetizamos las especulaciones poéticas de Parménides. ${ }^{36}$ En realidad, no puede haber respuesta, la realidad simplemente es real. Lo evidente no se demuestra, tan solo se muestra. Así que cada persona debe sobrellevar esa pregunta mientras vive, respondiéndola en sus determinaciones y quehaceres cotidianos. El caso es que, dado que vivimos, presuponemos un sentido, al menos parcial, nimio o mínimo, en todo cuanto hacemos. El sinsentido nos paralizaría. Entonces, vuelta la burra al trigo, ¿cuál es el sentido de la vida? No hay respuesta objetiva, uniforme, universal. Cada cual, en su unicidad, ha de descubrir sus propias soluciones, decidir un sentido subjetivo, construirlo al mismo tiempo que vive.

Afirmar un significado de la existencia es imprescindible, la clave de la salud física y mental. El psiquiatra austriaco judío Viktor Frankl, superviviente de los campos de exterminio, lo experimentó en carne y repitió luego en sus libros: sobrevivieron a la locura nazi no los más fuertes ni sanos ni inteligentes, sino los que se agarraron a la mínima la esperanza. El bienestar psíquico cuelga generalmente de tener un propósito en la vida. El método curativo que propone es la "logoterapia", traduciendo la palabra griega lógos por sentido, por tanto, la ayuda prestada al paciente para encontrar la razón de su existencia. ${ }^{37}$ Podríamos denominar esta búsqueda de sentido, siguiendo su idea, como logología, aunque parezca un palabro. Al final, el significado de las cosas, el sentido de la vida, es una decisión personal. Pa-

\footnotetext{
${ }^{34}$ Teeteto $155 \mathrm{~d}$.

${ }^{35}$ D. NetTle, Felicidad. La ciencia tras la sonrisa, Barcelona 2006, 136 ss.

${ }^{36}$ Fragmentos 5.

${ }^{37}$ V. FRANKL, El hombre en busca de sentido, Barcelona 2004, 119ss.
} 
rafraseando al poeta: no hay sentido, se hace sentido al vivir; o reinterpretando al filósofo: la vida es voluntad de sentido. ${ }^{38}$

La fe cristiana es, entre otras cosas, una propuesta de sentido. La mística evangélica del reino de Dios podríamos resumirla como amor incondicional divino. La vida es un don, una gracia, sencillamente una oportunidad que no hemos ganado. Y es lo único que tenemos. Debemos aprovecharla como se hace con los regalos hermosos: disfrutarla al máximo sin complejos ni culpa ${ }^{39}$ con el espíritu agradecido y humilde de quien sabe que no la ha merecido, arrostrando sus golpes y oscuridades como el precio a pagar. Esto se traducirá como esperanza firme, optimismo realista, la energía interior de saberse afortunado. No tiene que ver con la ingenuidad de creer que todo está bien, al contrario, es alegría profunda a pesar de los perennes males circundantes. El evangelio conjuga "ser sencillos como palomas y astutos como serpientes" (Mt 10,16). Todo formaría parte de la simbiosis entre el reino de Dios y la logología.

\section{Justicia desde la misericordia}

La fraternidad humana es una evidencia universal. A pesar de nuestras marcadas diferencias ideológicas, sociales, históricas, que nos han llevado a culturas opuestas y contumaces guerras, la igualdad de la especie nos envuelve cada amanecer como la luz y el aire. Poniéndonos un poco aristotélicotomistas, diríamos que las diferencias humanas son accidentes: altos o bajos, listos o menos, del Madrid o del Barça, mientras la igualdad subsiste como esencia: nacemos, vivimos y morimos condicionados por el azar y la voluntad.

Paradigma de esta percepción general de fraternidad es la llamada Regla de oro, la máxima "no hagas lo que no quieras que te hagan", que despunta en los albores de la civilización, expresada en el hinduismo y el confucianismo, atravesando el tiempo y el espacio sin aparente contacto entremedias, llegando al judaísmo (Tb 4,15) y a Marco Aurelio, desembocando también en el cristianismo (Mt 7,12) y encontrando depuración abstracta en la filosofía moderna: "obra de tal modo que consideres a la humanidad, en ti y en los otros, siempre como fin y nunca como medio". ${ }^{40}$

\footnotetext{
${ }^{38}$ A. Machado, Proverbios y cantares 29; F. Nietzsche, La voluntad de poder 252.

${ }^{39}$ Es destacable el cambio realizado en este punto por la Iglesia: VATiCAno II, Gaudium et spes 14; FRANCISCO, Christus vivit 145.

${ }^{40}$ Mahabharata 12,167; Confucio, Analectas 15,24; MArCO Aurelio, Meditaciones 7,22; I. KANT, Fundamentación de la metafísica de las costumbres 2.
} 
La cuestión es cómo encarnar la experiencia universal de fraternidad. La concreción más común ha nutrido la noción de justicia, etimológicamente la conformidad de algo a su naturaleza, la 'norma natural'. ${ }^{41} \mathrm{El}$ hombre es un ser social, necesita vivir en comunidad para desarrollarse, y la construcción de la sociedad precisa reglas de convivencia. La armonización de cada norma, ius, con las restantes devendrá la iustitia, el derecho. La concepción clásica de la justicia, de Platón al derecho romano, se tradujo en dar "a cada uno lo suyo", ofrecer a cada cual lo que le corresponde. Pero esto vino a desembocar en una justicia desigual, pues no se dispensaba el mismo trato a un hombre libre que a un esclavo. La intuición de la justicia natural de la fraternidad chocó, pues, desde los primeros instantes con una justicia social desequilibrada, variable, clasista. La historia de la humanidad será una confrontación irresuelta en pos de una sociedad más justa. Si las guerras provienen del ansia de poder, las revoluciones se anclan en el sentimiento de injusticia.

El evangelio reclama la igualdad sin más, reivindicando la fraternidad sencilla de la familia humana proveniente de Dios. Propone que nadie debe hacerse llamar maestro ni padre ni jefe, que nadie se sitúe sobre los demás, "pues todos vosotros sois hermanos" (Mt 23,8). Jesús fue un reformador religioso: corregía la ley, relativizaba el culto, decía que Dios es bueno igualmente con todos, también pecadores redomados, como publicanos y prostitutas, también enfermos y pordioseros, castigados por Dios (Mt 9,13). Fue asimismo un reformador social: criticaba la riqueza como principio de corrupción, "no podéis servir a Dios y el dinero" (Lc 16,13), hoy como ayer, "qué difícil es que un rico entre en el reino de Dios" (Lc 18,24); se solidarizaba con los pobres y marginados, a los que llamaba "bienaventurados" o preferidos de Dios (Mt 5,3ss). Tales apuntes reformadores conllevaban una crítica política: si parecía que pasaba de ella, al césar lo que es del césar (Mc 12,17), en realidad denostaba el poder y a los poderosos: es una tentación diabólica, los que gobiernan siempre se aprovechan (Mc 10,42). Su enseñanza y comportamiento aunaba a ricos y pobres, sanos y enfermos, piadosos y pecadores, adultos y niños ante la misma interpelación favorable de Dios. Como bien interpretó Pablo, "en Cristo no hay judío ni griego, ni esclavo ni libre, ni hombre ni mujer" (Gal 3,28).

Esta idea de igualdad simple o fraternidad implica misericordia -literalmente: pena del corazón, coloquialmente: compasión- hacia los desca-

${ }^{41}$ W. MANN - J. PIEPER, Justicia: H. Fries (ed), Conceptos fundamentales de teología, II, Madrid 1966, 463-480. 
balgados de la sociedad, los desafortunados y desechados, sea por las circunstancias de la vida o por las malas decisiones o por la inextricable combinación de ambas. La justicia misericordiosa es la corrección del infortunio con una solidaridad que lo compense. Parecerá entonces que se desdeña la justicia retributiva clásica, que se promueve la vagancia, que se desestima el mérito. En realidad es la conciencia de la igualdad de los hijos de Dios, que nos impulsa a levantar a los descartados por la vida o la sociedad o por sí mismos. Es la sensación de que no somos tan distintos, solo que algunos han tenido peor suerte y es preciso asistirlos. Podría pasarnos a cualquiera, y entonces nos gustaría ser ayudados. Es el reverso positivo de la regla de oro: hoy por ti, mañana por mí.

Para el cristianismo la misericordia no anula la justicia, sino que la supone y completa. Pues la misericordia sin justicia no es más que un vulgar paternalismo; pero la justicia sin misericordia deviene desigual, paradójicamente injusta.

$* * * * *$

El evangelio es eterno, de validez intemporal, y un cristianismo arreligioso, ecuménico, de agradecimiento y misericordia, de esperanza y fraternidad, será su necesaria actualización. La esencia misionera de la Iglesia, el testimonio de la fe de un modo comprensible para los hombres de su tiempo, le obliga a esa acomodación. El cristianismo existencial, de mística y ética, es la vanguardia del evangelio y su versión más antigua, el puente tendido a la mentalidad moderna, el confín habitable con la cultura arreligiosa. Sin renegar de la fe y tradición cristianas, pero igualmente sin imponerlas, no hay otro sendero practicable, es un intento de superación de las fronteras.

"Las palabras antiguas han de marchitarse y enmudecer, y nuestra existencia de cristianos solo tendrá dos aspectos: orar y hacer justicia entre los hombres". ${ }^{42}$

\footnotetext{
${ }^{42}$ D. Bonhoeffer, Resistencia y sumisión. Cartas y apuntes desde el cautiverio, V.1944.
} 